\title{
EFEITO DA IRRIGAÇÃO, ÉPOCAS DE CORTE DAFORRAGEM E DOSES DE NITROGÊNIO SOBRE O RENDIMENTO DE SEMENTES DE MILHETO ${ }^{1}$
}

\author{
JOÃO BATISTAJORNADADAJORNADA², RENATO BORGESDE MEDEIROS², CARLOSEDUARDODASILVAPEDROSO², \\ JOÃO CARLOS DE SAIBRO ${ }^{3}$, MARCELO ABREU DASILVA $^{3}$
}

\begin{abstract}
RESUMO - O experimento foi conduzido na Estação Experimental Agronômica/UFRGS, (3005’52"S; $51^{\circ} 40^{\prime} 08^{\prime \prime} \mathrm{W}$ ) com o objetivo de avaliar o efeito da irrigação (irrigado e não irrigado), de duas épocas de remoção da forragem (E1- remoção de aproximadamente 50\% dos ápices dos meristemas apicais dos perfilhos primários e E2- remoção de 75\%) e de quatro doses de nitrogênio (0, 50, 100 e $\left.150 \mathrm{~kg} \cdot \mathrm{ha}^{-1}\right)$, sobre os componentes de rendimento e o rendimento de sementes de milheto (Pennisetum americanum (L.) Leeke). O delineamento experimental utilizado foi parcela subsubdividida com quatro repetições. A semeadura foi realizada com máquina de plantio direto no dia 29/12/00. As doses de $N$ foram parceladas em duas aplicações iguais, sendo a primeira em 16/01/01 e a segunda uma semana após os cortes em E1 e E2. Os cortes foram realizados a uma altura de 20cm (E1=09/02 e E2=19/02) e a colheita de sementes nos dias 30/04 e 01/05. A aplicação de doses de N teve influência sobre os componentes de rendimento, tais como, número de panículas. ${ }^{-2}$, número de panículas com sementes. $\mathrm{m}^{-2}$, comprimento de panícula, peso de panícula e número de sementes.panícula ${ }^{-1}$. O componente panículas com sementes respondeu ao efeito das interações entre irrigação com doses de nitrogênio e épocas de corte com doses de nitrogênio. Maiores pesos de panícula e de mil sementes foram registrados no corte precoce (E1). O rendimento de sementes puras viáveis foi influenciado pelas épocas de corte e doses de nitrogênio, e no ponto de maior eficiência técnica do $\mathrm{N}\left(120 \mathrm{~kg} \cdot \mathrm{ha}^{-1}\right)$, foi de $769 \mathrm{~kg} \cdot \mathrm{ha}^{-1}$. Os componentes do rendimento que mais se correlacionaram com o rendimento de sementes foram o número de sementes.panícula ${ }^{-1} \mathrm{e}$ o peso de mil sementes. O rendimento de matéria seca total respondeu às doses de $\mathrm{N}$, sendo expresso por uma regressão linear positiva. A irrigação não afetou a resposta das variáveis estudadas.
\end{abstract}

Termos para indexação: Pennisetum americanum, componentes de produção, pastagem anual.

\section{EFFECT OF IRRIGATION, CLIPPING DATES AND NITROGEN RATES ON SEED YIELD OF PEARL-MILLET}

\begin{abstract}
A field trial was carried out at the Estação Experimental Agronômica/UFRGS

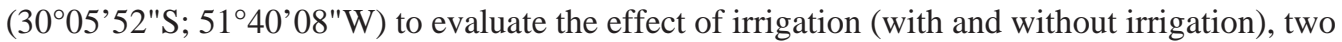
clipping dates (E1- removing about $50 \%$ of the apical meristems of the primary tillers; E2- removing $75 \%$ ), and four rates of nitrogen (0, 50, 100, and $\left.150 \mathrm{~kg} \cdot \mathrm{ha}^{-1}\right)$ on seed yield of pearl-millet (Pennisetum americanum (L.) Leeke). The experiment was arranged in a randomized split-split-plot design with four replications. Seeding was performed by direct drilling, on December 29, 2000. Nitrogen rates were equally split and broadcast, half in January 16, 2001 and half one week after clipping. The clippings were done at $20 \mathrm{~cm}$ height, $(\mathrm{E} 1=02 / 09$ and $\mathrm{E} 2=02 / 19)$ and the seed was harvested in April 30 and May 01, 2001. Nitrogen applications influenced seed yield components such as: total number of panicles. $\mathrm{m}^{-2}$, number of panicles with seeds. $\mathrm{m}^{-2}$, length of panicles, weight of panicles and number of seeds.panicle ${ }^{-1}$. The component panicles with seeds were affected by the interactions
\end{abstract}

\footnotetext{
${ }^{1}$ Submetido em 11/06/2004. Aceito para publicação em 22/06/2005. Parte da dissertação apresentada à Universidade Federal do Rio Grande do Sul (UFRGS), pelo primeiro autor.

${ }^{2}$ Engenheiro Agrônomo, MSc, UFRGS, Av Bento Gonçalves, 7712, Bairro Agronomia, Cep. 91.540-000, Porto Alegre, RS. jornadajb@ig.com.br
}

\footnotetext{
${ }^{3}$ Engenheiro Agrônomo, Dr., professor adjunto, Departamento de Plantas Forrageiras e Agrometeorologia (DPFA), UFRGS, Av Bento Gonçalves, 7712, Bairro Agronomia, Cep. 91.540-000, Porto Alegre, RS.
} 
between irrigation and nitrogen rates, and clipping and nitrogen rates. Higher weights of panicles and thousand seeds were registered in early clipping (E1). The viable pure seed yield at the maximum technical efficiency of $\mathrm{N}\left(120 \mathrm{~kg} \cdot \mathrm{ha}^{-1}\right)$ was $769 \mathrm{~kg} \cdot \mathrm{ha}^{-1}$. The seed yield components that correlated significantly with seed yield were number of seeds.panicle ${ }^{-1}$ and weight of one thousand seeds. The total dry matter yield was influenced by the nitrogen rates, which was described by a positive linear regression. Irrigation did not affect any of the studied variables.

Index terms: Pennisetum americanum, yield components, annual pasture.

\section{INTRODUÇÃO}

As gramíneas anuais de verão formam pastagens economicamente atrativas, destacando-se sua participação nos sistemas intensivos de produção. Dentre estas espécies, o milheto (Pennisetum americanum (L.) Leeke) se destaca devido à capacidade de adaptação às condições edafoclimáticas do sul do Brasil e a alta produção de forragem de qualidade (Medeiros et al., 1978; Maraschin, 1979; Moraes et al., 1995), sendo utilizado especialmente em pastejo direto ou para silagem. Os produtores cultivam estas espécies prioritariamente para a alimentação animal, utilizando a pastagem até o final do seu crescimento, sendo que poucos utilizam estratégias, como o diferimento ou outras práticas de manejo, visando à produção de sementes.

Dentre estas práticas, a adubação nitrogenada constitui uma importante ferramenta a ser utilizada. O nitrogênio influencia positivamente os componentes de rendimento e, conseqüentemente, o rendimento de sementes. A literatura relata respostas ao $\mathrm{N}$ para comprimento de panícula e peso de mil sementes de milheto (Scheffer et al., 1985), peso de panícula, comprimento de panícula e peso de mil sementes em sorgo (Sorghum bicolor) (Subba Reddy et al., 1991) e número total de perfilhos, perfilhos férteis, número de panículas e comprimento de panícula de milheto (Mesquita et al., 1998).

A desfolha, seja realizada através de corte ou pastejo, é outra prática comumente utilizada em áreas de produção de sementes. Do ponto de vista prático, é utilizada para estimular o perfilhamento, obter maior sincronização no florescimento e minimizar as possibilidades de acamamento. No caso específico da produção de sementes de milheto no estado do Rio Grande do Sul, o acamamento das plantas durante a maturidade da semente dificulta a colheita, ocasionando perdas de rendimento e da qualidade da mesma.

A identificação da intensidade da remoção da forragem e a época de diferimento do pastejo foram estudadas durante dois anos por Young et al. (1996). Neste trabalho, os rendimentos de sementes de azevém anual nas três intensidades de utilização (um terço, dois terços e todos os perfilhos primários em elongação visível ou palpável removidos) não diferiram dos rendimentos obtidos do tratamento sem pastejo. Os autores registraram, também, uma redução no índice de área foliar e do acamamento pela redução do porte das plantas.

A irrigação pode incrementar a produtividade das lavouras destinadas à produção de sementes, especialmente, nos casos em que a umidade do solo é limitante, para garantir um bom desenvolvimento vegetativo antes da floração. O déficit hídrico reduz, de maneira acentuada, a velocidade de alongamento das folhas, embora haja diferenças entre as espécies quanto ao nível do potencial hídrico a partir do qual a velocidade é afetada (Nabinger e Medeiros, 1995).

O estudo destas e de outras práticas de manejo é muito importante para otimizar os sistemas mistos de produção de forragem e de sementes, proporcionando uma remuneração extra ao produtor. Dentro deste contexto, foi conduzido um trabalho, objetivando avaliar o efeito da irrigação, épocas de corte e doses de nitrogênio sobre os componentes de rendimento e o rendimento de sementes de milheto.

\section{MATERIALE MÉTODOS}

O experimento foi conduzido na Estação Experimental Agronômica da Universidade Federal do Rio Grande do Sul, Eldorado do Sul, (3005’52" S e 51 ${ }^{\circ} 40^{\prime} 08^{\prime \prime} \mathrm{W}$; altitude de $46 \mathrm{~m}$ ) localizada na região ecoclimática da Depressão Central do Estado do Rio Grande do Sul (RS). O clima, segundo a classificação de Köppen, é do tipo Cfa (subtropical úmido com verão quente). Os dados meteorológicos como precipitação pluvial (mm), temperatura média $\left({ }^{\circ} \mathrm{C}\right)$ e radiação solar global (cal.cm-2.dia ${ }^{-1}$ ) foram coletados da Estação Meteorológica do Departamento de Plantas Forrageiras e Agrometeorologia da UFRGS, situada a 100 metros do local do experimento (Tabela 1). 
TABELA 1. Precipitação pluvial, temperatura média do ar e radiação solar global média (RSGM), durante o período experimental e o normal ocorrido na região de estudo (Departamento de Plantas Forrageiras e Agrometeorologia da UFRGS).

\begin{tabular}{ccccccc}
\hline & \multicolumn{2}{c}{ Precipitação pluvial $(\mathrm{mm})$} & \multicolumn{2}{c}{ Temp. média do ar $\left({ }^{\circ} \mathrm{C}\right)$} & \multicolumn{2}{c}{ RSGM $\left(\mathrm{cal} / \mathrm{cm}^{2} / \mathrm{dia}^{1}\right.$} \\
& Ocorrida & Normal $^{1}$ & Ocorrida & Normal & Ocorrida & Normal \\
\hline Janeiro & 171,3 & 114,8 & 24,2 & 24,7 & 457 & 495 \\
Fevereiro & 121,5 & 107,6 & 25,0 & 24,8 & 451 & 444 \\
Março & 143,7 & 106,7 & 24,2 & 23,3 & 103 & 393 \\
Abril & 290,9 & 101,8 & 20,2 & 19,7 & 277 & 319 \\
\hline
\end{tabular}

${ }^{1}$ Normais: padrão do período de 1970 a 1989 para precipitação e temperatura média e 1968 a 1988 para RSGM para Eldorado do Sul - RS.

Além destes dados, foram instalados “dataloggers” tipo Hobo, "Onset Computers" dentro do dossel a uma altura de $20 \mathrm{~cm}$ acima do nível do solo, que registraram a temperatura em intervalos regulares de 10 minutos. Estes dados serviram para calcular o somatório de graus-dia (GD) conforme a fórmula: GD = [(T Max + T $\mathbf{~ m i n}) / 2]-\mathbf{T}$ base, com T base utilizada de $12^{\circ} \mathrm{C}$ (Garcia-Huidobro et al., 1982). As datas das principais práticas de manejo, com respectivos GD, encontram-se na Tabela 2.

O experimento foi estabelecido em solo pertencente à unidade de mapeamento Arroio dos Ratos, classe taxonômica Plintossolo, apresentando a seguinte composição química: $\mathrm{pH}-$ $\mathrm{H}_{2} \mathrm{O}(1: 1)$ = 5,3; 22\% de argila; 1,2\% de matéria orgânica; 18mg. $\mathrm{L}^{-1}$ de $\mathrm{P}$ disponível; $130 \mathrm{mg} . \mathrm{L}^{-1}$ de $\mathrm{K}$ trocável e $0,3 \mathrm{cmol}_{\mathrm{c}} \cdot \mathrm{L}^{-1}$ de alumínio trocável.

$\mathrm{O}$ experimento constituiu-se num fatorial $2 \times 2 \times 4$. O delineamento experimental utilizado foi parcela sub-subdividida com as parcelas principais arranjadas em blocos completos casualizados, sendo os tratamentos níveis de irrigação (I irrigado e NI - não irrigado) alocados nas parcelas principais, épocas de corte (E1- remoção de aproximadamente 50\% dos ápices dos meristemas apicais dos perfilhos primários e E2remoção de $75 \%$ ) nas subparcelas e doses de nitrogênio $\left(\mathrm{N} 1=0, \mathrm{~N} 2=50, \mathrm{~N} 3=100\right.$ e $\left.\mathrm{N} 4=150 \mathrm{~kg} \cdot \mathrm{ha}^{-1}\right)$ nas subsubparcelas com 4 repetições, totalizando 64 parcelas. As subsubparcelas tinham dimensão de $8 \times 3,2 \mathrm{~m}$, com 8 linhas espaçadas de $0,4 \mathrm{~m}$, considerando-se como bordadura duas linhas em cada extremidade lateral e $1 \mathrm{~m}$ em cada cabeceira.

Com a finalidade de preparar o solo para a semeadura direta do milheto foram aplicados $5 \mathrm{~L} . \mathrm{ha}^{-1}$ do herbicida glifosato em $1^{\circ} / 12$ e $28 / 12$. A semeadura foi realizada no dia $29 / 12 /$ 2000, com densidade de plantio de $25 \mathrm{~kg} \cdot \mathrm{ha}^{-1}$ de sementes com germinação de $80 \%$ e pureza de $97,6 \%$. A adubação de base foi realizada na linha na dosagem de $200 \mathrm{~kg}$ ha $^{-1}$ da fórmula 5-20-20. Visando assegurar uma germinação uniforme foram realizadas duas irrigações de $30 \mathrm{~mm}$, em toda a área experimental. No período experimental houve um controle satisfatório das plantas indesejadas, pragas e controle de pássaros durante o período de formação e maturação das sementes.

Por ocasião do plantio, todos os tratamentos receberam uma adubação de base de $20 \mathrm{~kg}$.ha-1 ${ }^{-1}$. As dosagens de nitrogênio previstas nos tratamentos N2, N3 e N4 foram divididas em duas aplicações, sendo a primeira realizada em 16/01, por ocasião do início do perfilhamento e a segunda, uma semana após a realização do corte, em fevereiro, ambas sob a forma de uréia. A adubação foi manual e ao lado da linha de plantio.

Para a aplicação do tratamento de irrigação, foi instalado um sistema por aspersão nas parcelas correspondentes. O critério utilizado para efetuar a irrigação baseou-se no monitoramento da diferença entre a precipitação e a evaporação do tanque classe A, que quando atingia 30mm indicava que uma irrigação deveria ser aplicada (Rojas, 1998).

Os tratamentos de remoção da forragem foram aplicados a uma altura de $20 \mathrm{~cm}$ acima do nível do solo, com uma segadeira, em duas épocas distintas, baseados na altura do meristema apical da haste primária. A primeira época de remoção da forragem (E1) foi realizada em 09/02 (937 grausdia), quando a altura média de 50\% dos meristemas apicais

TABELA 2. Datas das principais práticas de manejo realizadas no experimento com as respectivas somas térmicas em graus-dia (GD).

\begin{tabular}{clr}
\hline Data & \multicolumn{1}{c}{ Prática } & GD \\
\hline $29 / 12 / 00$ & Semeadura & 0 \\
$04 / 01 / 01$ & Final da germinação & 0 \\
$11 / 01$ & Aplicação de inseticida & 182 \\
$16 / 01$ & Adubação de cobertura & 303 \\
$09 / 02$ & $1^{\text {a }}$ época de corte (E1) & 937 \\
$16 / 02$ & Adubação de cobertura em E1 & 1114 \\
$19 / 02$ & $2^{\text {a }}$ época de corte (E2) & 1193 \\
$23 / 02$ & Capina do E1 & 1305 \\
$26 / 02$ & Adubação de cobertura em E2 & 1395 \\
$12 / 03$ & Capina do E2 & 1793 \\
$30 / 04$ & Colheita do E1 & 2921 \\
$01 / 05$ & Colheita do E2 & 2945 \\
\hline
\end{tabular}


das hastes primárias ultrapassou a altura de $20 \mathrm{~cm}$. A segunda época (E2) foi aplicada em 19/02 (1193 graus-dia), quando a altura média de aproximadamente $75 \%$ dos meristemas apicais dos perfilhos primários se encontrava acima de $20 \mathrm{~cm}$. Para determinação da altura do meristema apical dos perfilhos de milheto, foram retiradas amostras aleatórias de plantas das bordaduras a cada dois dias, entre os dias 02 e 08/02. Os colmos foram seccionados ao meio com auxílio de um estilete. Assim, o meristema apical tornou-se visível e foi medida a altura em que se encontrava, a partir da base da planta. No dia 19/02 foram colhidas amostras no tratamento E2, conforme descrito anteriormente. A massa verde colhida da área útil foi pesada em um dinamômetro tipo "Milkscale”, retirando-se uma subamostra de, aproximadamente, $1 \mathrm{~kg}$ para a determinação parcial da matéria seca. Estas subamostras foram colocadas em estufas com ar forçado a $60^{\circ} \mathrm{C}$ por 72 horas e posteriormente pesadas.

A colheita de sementes foi realizada nos dias 30/04 (2921 GD) e 1\%05/2001 (2945 GD) nos tratamentos E1 e E2, respectivamente. Primeiramente, procedeu-se o corte apenas das panículas, na área útil, com o auxílio de uma tesoura. Posteriormente, cortou-se a biomassa remanescente na área referida, sendo retirada uma subamostra para a determinação da matéria seca. As panículas foram colocadas em sacos de algodão para posterior secagem e determinação dos componentes de rendimento.

As panículas foram separadas em panículas com semente $\left(\mathrm{NPCS} \cdot \mathrm{m}^{-2}\right.$ ) e panículas que não completaram o seu desenvolvimento (panículas sem sementes $-\mathrm{NPSS}^{-2} \mathrm{~m}^{-2}$ ). As panículas com sementes foram colocadas sobre uma mesa e dispostas uma ao lado da outra, em ordem crescente de tamanho para a determinação de outros componentes. Para a determinação do comprimento e peso médio de panícula, retirou-se uma amostra de 15 panículas (da fração com sementes) em intervalos regulares, obtidos pela divisão do número total de panículas por 15. Esta amostra foi pesada e utilizada para a determinação do comprimento médio de panícula (CMP). O CMP foi obtido pela média aritmética dos comprimentos das panículas. O número médio de sementes por panícula foi determinado através dos dados do rendimento de sementes, número de panículas e do peso de mil sementes (P1000).

Os sacos de algodão contendo as panículas foram colocados em um secador de leito fixo, cilíndrico, com tela e ventilação com ar forçado e secagem a gás. Utilizou-se temperatura aproximada de $35^{\circ} \mathrm{C}$ durante 72 horas. O material, então, foi trilhado em trilhadeira estacionária de parcelas estacionária, sendo acondicionado em sacos de papel, para posterior pesagem e limpeza. A determinação da pureza, do P1000 e do grau de umidade das sementes seguiu metodologia das Regras para Análise de Sementes (Brasil, 1992).

Os dados foram submetidos à análise de variância. Os efeitos de irrigação e corte, quando significativos, foram submetidos ao teste de Duncan, sendo o nível mínimo de significância aceito de 5\%. Quanto ao efeito do nitrogênio, quando significativo, foi submetido à análise de regressão, testando-se os modelos linear e quadrático, em busca de um modelo que melhor expressasse esta relação, com nível de significância de 5\%. As análises foram efetuadas pelo programa SANEST (Zonta et al.,1984). Efetuou-se análise de correlação entre os componentes de rendimento com o rendimento de sementes e, posteriormente, análise de trilha com o auxílio do aplicativo computacional em genética e estatística (GENES), versão 98.1.0 (Cruz, 2001), visando expressar a associação direta e indireta dos componentes com o rendimento de sementes.

\section{RESULTADOS E DISCUSSÃO}

A aplicação de doses de $\mathrm{N}$ teve influência sobre os componentes de rendimento de sementes de milheto, tais como, número de panículas.m ${ }^{-2}\left(\mathrm{NP} . \mathrm{m}^{-2}\right)$, número de panículas com sementes. $\mathrm{m}^{-2}$ (NPCS. $\left.\mathrm{m}^{-2}\right)$, comprimento médio de panícula (CMP), peso de panícula (PP) e número de sementes.panícula-1 ${ }^{-1}$ (NSP). Quanto às panículas com sementes, houve interação entre irrigação com doses de nitrogênio e épocas de corte com doses de nitrogênio. A época de corte influenciou o PP e o P1000. A irrigação praticamente não alterou a resposta das variáveis avaliadas, provavelmente, devido à precipitação elevada durante o período experimental (Tabela 1).

O número de panículas.m ${ }^{-2}$ (NP) aumentou com as doses de N, esta relação foi melhor explicada por regressão linear (Tabela 3). Com a mesma espécie, Mesquita et al. (1998) obtiveram resposta semelhante, utilizando doses de até $180 \mathrm{~kg}$ de N.ha' ${ }^{-1}$.

Analisando o componente NPCS. $\mathrm{m}^{-2}$ na interação irrigação e doses de $\mathrm{N}$, o tratamento não irrigado (NI) foi melhor explicado por uma regressão quadrática com o ponto de máxima eficiência técnica de $114 \mathrm{~kg}$ de N.ha- ${ }^{-1}$ e o irrigado (I) por uma regressão linear frente às doses de $\mathrm{N}$ (Figura 1 ). Esta queda no NPCS.m-2 ${ }^{2}$, ocorrida no nível máximo de N, no tratamento não irrigado pode ser explicada pela possível ocorrência de déficit hídrico após a aplicação de N, na primeira 


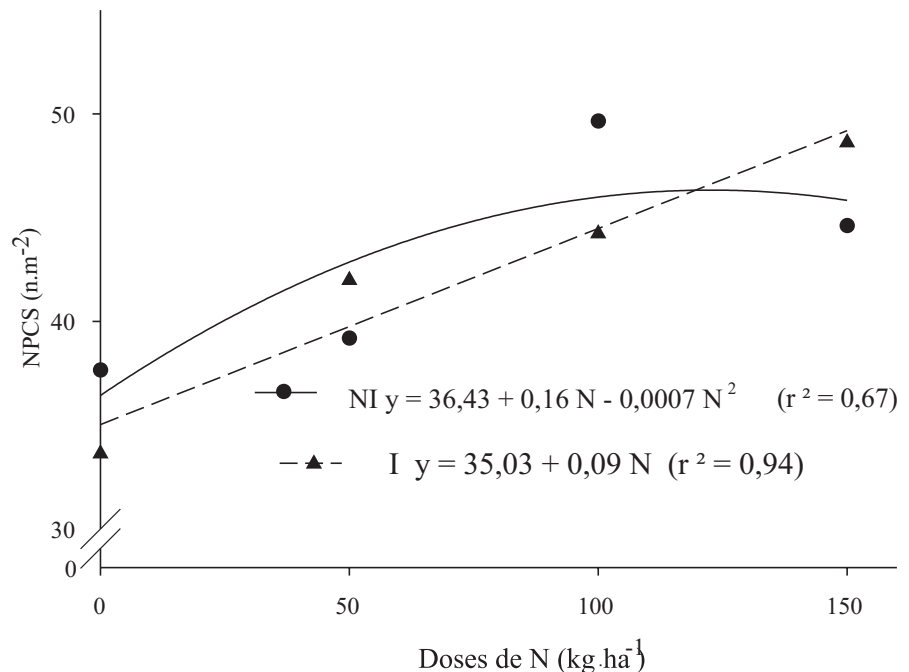

FIGURA 1. Número de panículas com sementes (NPCS) de milheto em função da interação entre níveis de irrigação (NI e I) e doses de nitrogênio.

época de corte. Uma parte desse $\mathrm{N}$ pode ter sido perdida por volatilização, prejudicando assim, sua absorção e translocação na planta, não permitindo um rebrote vigoroso e, conseqüentemente, o desenvolvimento de panículas bem formadas. Quanto ao irrigado, houve um crescimento linear, demonstrando o melhor aproveitamento do $\mathrm{N}$ com níveis satisfatórios de umidade.

Com relação à interação épocas de corte e doses de nitrogênio houve um acréscimo linear do NPCS.m ${ }^{-2}$ em E1. Em todas as doses de $\mathrm{N}$, este elemento se mostrou superior à $\mathrm{E} 2$, que apresentou resposta quadrática frente às doses de $\mathrm{N}$ (Figura 2), ou seja, a remoção mais drástica dos meristemas apicais em E2 determinou menores quantidades de panículas.m², em todos os níveis de $\mathrm{N}$.

O maior NPCS. $\mathrm{m}^{-2}$ em E1, pode ser atribuído a maior porcentagem de perfilhos principais remanescentes após o corte do que em E2. O maior vigor e acúmulo de fotoassimilados dos perfilhos principais em E1, conferemlhes maior taxa de transformação de perfilhos vegetativos em reprodutivos, formando mais panículas com sementes $\left(\mathrm{NPCS}_{\mathrm{m}} \mathrm{m}^{-2}\right.$ ) do que os perfilhos originados de E2. Isto significa que o retardamento do corte em apenas 10 dias provocou reduções significativas no número de panículas. $\mathrm{m}^{-2}$. Cabe ressaltar que, nesses 10 dias, foram registradas altas temperaturas dentro do dossel, acumulando uma soma térmica de $256^{\circ} \mathrm{C}$ (Tabela 2) que, aliado ao efeito da alta disponibilidade de água (Tabela 1), criou uma condição ótima de rebrote e crescimento dos perfilhos em E1. É possível especular que esse período estabeleceu, já nesta fase, uma diferença

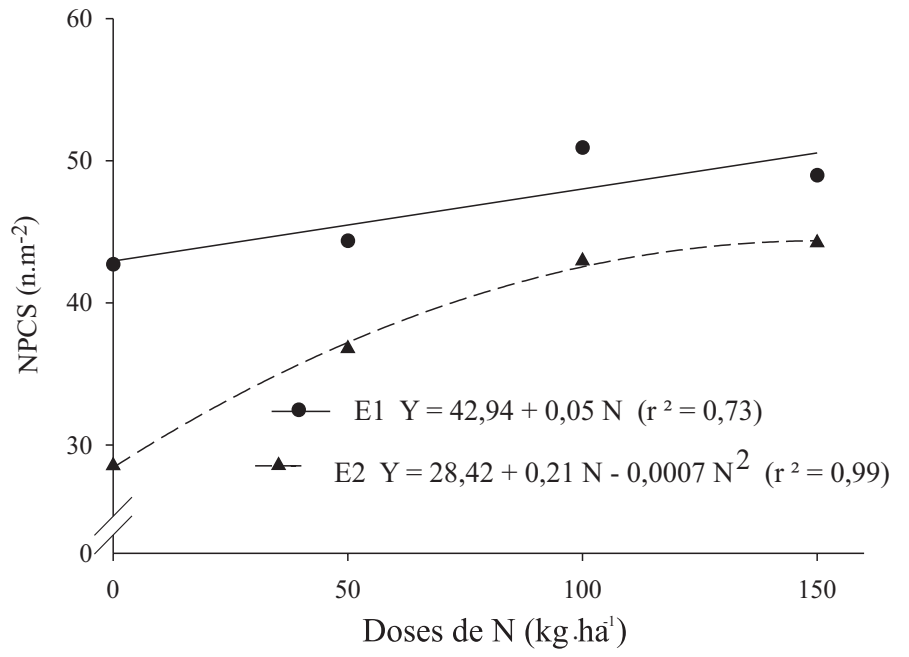

FIGURA 2. Número de panículas com sementes (NPCS) de milheto em função da interação entre épocas de corte $\left(E_{1}\right.$ e $\left.E_{2}\right)$ e doses de nitrogênio.

importante na capacidade de captação de energia dos perfilhos em E1.

A análise de variância revelou como significativa uma regressão linear como modelo para expressar a resposta do NPSS.m ${ }^{-2}$ ao nitrogênio, a um nível de significância de 5\%, porém biologicamente, esta regressão não representa satisfatoriamente o comportamento de tal variável. Realizando um teste de comparação de médias, percebe-se que somente na ausência de $\mathrm{N}$ ocorreu maior número de panículas vazias, diferindo significativamente das demais doses, quando este número tendeu a se estabilizar em níveis mais baixos (Tabela 4). Torna-se evidente que este nutriente é de crucial importância na produção de sementes, pois na ausência de N em cobertura, há maior número de panículas vazias. Podese concluir que o $\mathrm{N}$ presente no solo, somado à adubação de base, não foram suficientes para assegurar eficiente transformação de perfilhos vegetativos em reprodutivos. Quanto às épocas de corte, o NPSS.m-2 foi superior em E2 $(14,74)$ em relação à E1 $(7,82)$, devido ao crescimento subseqüente ao corte E2 ser baseado em menor número de perfilhos principais e, provavelmente, em perfilhos secundários de vigor inferior aos perfilhos secundários formados em E1.

A aplicação de doses crescentes de $\mathrm{N}$ ocasionou um aumento no CMP de milheto, sendo esta relação melhor explicada por uma regressão linear (Tabela 3). Resposta semelhante foi obtida por Scheffer et al. (1985) e Mesquita et al. (1998). Carámbula e Elizondo (1968) constataram que um dos maiores benefícios do $\mathrm{N}$ na produção de sementes de gramíneas forrageiras é o aumento do número de espiguetas 
TABELA 3. Equações de regressão ajustadas e coeficiente de determinação do total de panículas, comprimento de panícula(CMP) e peso de panícula (PP) de milheto em função da adubação nitrogenada.

\begin{tabular}{llc}
\hline \multicolumn{1}{c}{ Variáveis } & Equações ajustadas & $\mathrm{R}^{2}$ \\
\hline Número de panículas.m $^{-2}$ & $\mathrm{Y}=49,74+0,05 \mathrm{X}$ & 0,84 \\
Comprimento médio de panícula $(\mathrm{cm})$ & $\mathrm{Y}=16,71+0,01 \mathrm{X}$ & 0,97 \\
Peso de panícula $(\mathrm{g})$ & $\mathrm{Y}=4,38+0,01 \mathrm{X}$ & 0,92 \\
Número de sementes por panícula & $\mathrm{Y}=394,44+0,59 \mathrm{X}$ & 0,68 \\
\hline
\end{tabular}

e do tamanho das inflorescências. Segundo Quendeba et al. (1993), o comprimento da panícula é importante critério utilizado pelos produtores na seleção de panículas de milheto para a obtenção de sementes para o plantio.

O PP variou para épocas de corte, sendo que a E1 apresentou um peso de 5,98g e foi significativamente superior à E2 $(4,33 g)$. Quanto às doses de $\mathrm{N}$, o comportamento foi melhor explicado por regressão linear positiva (Tabela 3). $\mathrm{O}$ peso médio de panícula reflete o tamanho da mesma e está relacionado, principalmente, com o comprimento e número de sementes por panícula que responderam positivamente às doses de nitrogênio.

O número de sementes por panícula aumentou linearmente com o aumento da adubação nitrogenada (Tabela 3). Isto significa que à medida que aumenta a quantidade de $\mathrm{N}$ no solo aumenta a taxa de transformação de flores em sementes e, conseqüentemente, eleva o potencial de produção de sementes por unidade de área.

O P1000 variou em função das épocas de corte, sendo maior em E1 (4,830g) do que em E2 (4,130g). O N não influenciou o PMS de milheto, concordando com Roy e Wright (1973), Scheffer (1981) e Mesquita (1996).

A análise de variância revelou significância para o efeito de épocas de corte e de doses de $\mathrm{N}$ sobre o rendimento de sementes puras viáveis (RSPV) de milheto. O RSPV foi significativamente superior em E1, 861,47kg.ha ${ }^{-1}$ do que em E2, 491,94kg.ha-1 ${ }^{-1}$ Percebe-se que o manejo do corte, baseado no monitoramento da altura do meristema apical, pode influenciar positiva ou negativamente o rendimento de sementes. No presente trabalho, com uma diferença de apenas 10 dias ou 256 graus-dia, o corte realizado em E1 apresentou um rendimento $75 \%$ superior ao corte realizado em E2. Acredita-se que o maior rendimento em E1 seja o reflexo direto da maior quantidade de perfilhos principais com meristemas apicais presentes. Esta condição de população em E1, com perfilhos mais vigorosos do que em E2, resultou em maior número de sementes.panícula ${ }^{-1}$ e sementes mais pesadas, contribuindo assim para o maior rendimento em E1.
Este efeito tem sido relatado na literatura (Carámbula, 1981; Nabinger e Medeiros, 1995).

Quanto à resposta do RSPV frente às doses de $\mathrm{N}$, a Figura 3 mostra que a relação foi melhor explicada por uma regressão quadrática com o ponto de máxima eficiência técnica estimado na dose de $120 \mathrm{~kg}$ de N.ha ${ }^{-1}$. Respostas semelhantes do rendimento de sementes ao $\mathrm{N}$ aplicado foram obtidas por Scheffer et al. (1985) e Mesquita et al. (1998). Mesquita et al. (1998), utilizando dosagens de até $180 \mathrm{~kg}$ de N.ha ${ }^{-1}$ em milheto encontraram resposta quadrática frente às doses de $\mathrm{N}$, com máxima eficiência técnica estimada em 115kg de N.ha-1.

A análise de trilha apresentou a correlação entre os componentes de rendimento com o rendimento de sementes, bem como a decomposição desta correlação em efeito direto e indireto (Tabela 5). Os componentes total de panículas (TP), NPCS e CP apresentaram baixa correlação com o rendimento de sementes. O componente NSP apresentou maior correlação

TABELA 4. Efeito de doses de nitrogênio sobre o número de panículas sem sementes. $\mathrm{m}^{-2}$ de milheto.

\begin{tabular}{lc}
\hline Doses de Nitrogênio & Panículas sem sementes $/ \mathrm{m}^{2}$ \\
\hline 0 & $14,25 \mathrm{a}^{*}$ \\
50 & $10,58 \mathrm{~b}$ \\
100 & $10,15 \mathrm{~b}$ \\
150 & $10,16 \mathrm{~b}$ \\
\hline Média & 11,28 \\
\hline
\end{tabular}

*Médias seguidas de mesma letra não diferem entre si pelo teste de Duncan a $5 \%$

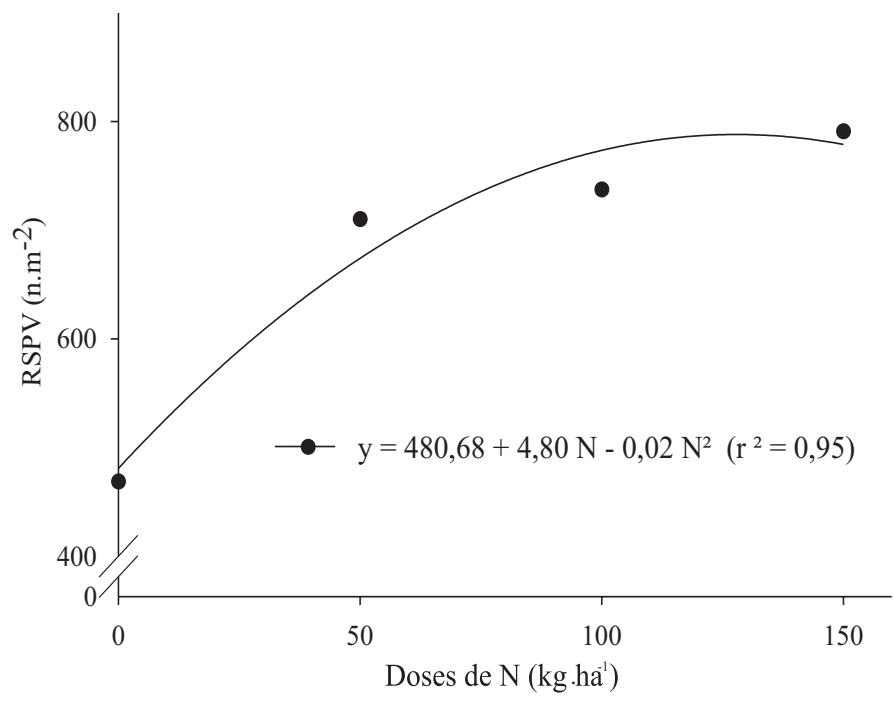

FIGURA 3. Rendimento de sementes puras viáveis (RSPV) de milheto em função de doses de nitrogênio. 
TABELA 5. Resultado da análise de trilha para rendimento de sementes, total de panículas (TP), panículas com sementes (PCS), comprimento de panícula (CP), sementes por panícula (SPP), peso de panícula (PP) e peso de mil sementes $(\mathrm{P} 1000)$ em milheto.

\section{VARIÁVEL $=>$ TP}

Efeito direto sobre rendimento de sementes

Efeito indireto via panículas com sementes

0,01681

0,20351

Efeito indireto via comprimento de panícula

Efeito indireto via sementes por panícula

Efeito indireto via peso de panícula

00421

$-0,00795$

$-0,00142$

0,02013

Total

\section{VARIÁVEL $=>$ PCS}

Efeito direto sobre rendimento de sementes $\quad 0,28359$

Efeito indireto via total de panículas $\quad 0,01206$

Efeito indireto via comprimento de panícula $\quad 0,00402$

Efeito indireto via sementes por panícula $\quad 0,02336$

Efeito indireto via peso de panícula $\quad-0,00084$

Efeito indireto via $\mathrm{p} 1000$

0,00970

Total

0,3319

VARIÁVEL $=>$ CP

Efeito direto sobre rendimento de sementes $\quad-0,03350$

Efeito indireto via total de panículas $\quad-0,00211$

Efeito indireto via panículas com sementes $\quad-0,03406$

Efeito indireto via sementes por panícula $\quad 0,23879$

Efeito indireto via peso de panícula $\quad 0,00303$

Efeito indireto via p1000 $\quad 0,06083$

Total

$\mathbf{0 , 2 3 3}$

\section{VARIÁVEL $=>$ SPP}

Efeito direto sobre rendimento de sementes $\quad 0,70380$

Efeito indireto via total de panículas $\quad-0,00019$

Efeito indireto via panículas com semertes $\quad 0,00941$

Efeito indireto via comprimento de panícula -0,01136

Efeito indireto via peso de panícula $\quad 0,00303$

Efeito indireto via p1000 $\quad 0,16890$

Total

VARIÁVEL $=>$ PP

Efeito direto sobre rendimento de sementes

Efeito indireto via total de panículas

Efeito indireto via panículas com sementes $\quad-0,03791$

Efeito indireto via comprimento de panícula $-0,01612$

Efeito indireto via sementes por panícula $\quad 0,33909$

Efeito indireto via p 1000

0,12650

Total

VARIAVEL $=======>P 1000$

Efeito direto sobre rendimento de sementes $\quad 0,25681$

Efeito indireto via total de panículas

0,00131

Efeito indireto via panículas com sementes $\quad 0,01072$

Efeito indireto via comprimento de panícula $-0,00793$

Efeito indireto viasementes por panícula $\quad 0,46288$

Efeito indireto via peso de panícula $\quad 0,00310$

Total com o rendimento de sementes, sendo aquele que mais contribuiu no efeito direto entre estas variáveis. Ainda na Tabela

5, pode ser constatado que o caráter PP e P1000 apresentaram média e alta correlação positiva, respectivamente. Geraldo et al. (2000), trabalhando com milheto pérola (Pennisetum glaucum (L.) R. Brown), constataram que a produção de grãos foi positivamente correlacionada com o P1000 e o comprimento de panículas e negativamente correlacionada com o número de panículas. Craufurd e Bidinger (1998) sugerem que, em milheto, a seleção que visa o aumento do número de panículas não deve resultar em aumento significativo no potencial produtivo, pela relação inversa com o tamanho da panícula e que o aumento na produção deve vir através do aumento do número de sementes.

A análise de variância revelou significância para o efeito do nitrogênio e épocas de corte sobre o rendimento total de MS de milheto. Os rendimentos encontrados para doses de $\mathrm{N}$ foram de 9.232; 10.649; 12.334 e 12.681 kg de MS.ha-1 , para N1, N2, N3 e N4 respectivamente, sendo melhor explicado por regressão linear (Figura 4). Isto significa que na maior dose de $\mathrm{N}$, a taxa de crescimento média é de $108 \mathrm{~kg}$ de MS.ha${ }^{1}$.dia ${ }^{-1}$. Lupatini et al. (1996), trabalhando com doses de $\mathrm{N}$ até $600 \mathrm{~kg} \cdot \mathrm{ha}^{-1}$, com a mesma espécie, registraram taxas de acumulação diária de até $150 \mathrm{~kg}$ de MS.ha-1 .

Em vários trabalhos realizados com milheto, foi constatado um aumento no rendimento de MS conforme aplicação de nitrogênio (Medeiros et al., 1978; Silveira et al., 1984; Scheffer et al., 1985; Lupatini et al., 1996; Mesquita e

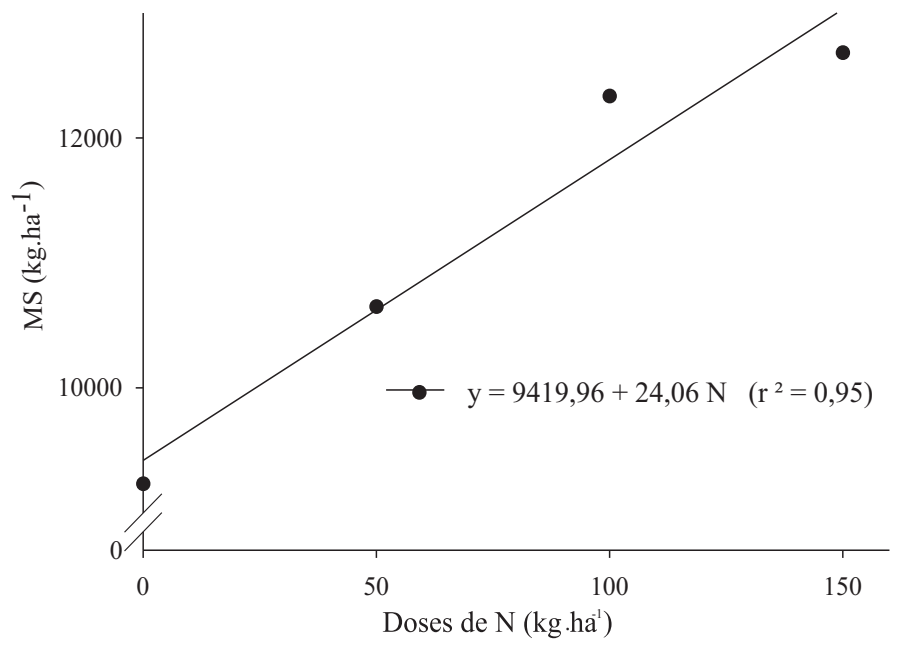

0,414

0,7269

FIGURA 4. Rendimento de matéria seca total (MS) de milheto em

\section{0,8736}

\section{função de doses de nitrogênio.}

Coeficiente de determinação $\quad 0,89440$

Efeito da variável residual $\quad 0,32495$ 
Pinto, 2000). Realizando quatro cortes da forragem de milheto e período de avaliação maior, Medeiros et al. (1978) obtiveram a máxima eficiência técnica utilizando a dose de 180kg.ha-1 quando o rendimento alcançou 16t de MS.ha ${ }^{-1}$.

Quanto à época de corte o rendimento de MS total da E1 foi superior a E2, com rendimentos de 11.965 e $10.483 \mathrm{~kg}$.ha${ }^{1}$, respectivamente. Este rendimento inferior pode ser atribuído à maior remoção dos meristemas apicais dos perfilhos principais na segunda época de corte, sendo o período subseqüente de crescimento baseado em perfilhos secundários e, portanto, menos vigorosos. Esta perda de vigor pode ser atribuída à redução na área foliar e nas reservas orgânicas das plantas ocasionadas pelo corte (Scheffer et al., 1985).

\section{CONCLUSÕES}

A aplicação de doses crescentes de N, até $150 \mathrm{~kg} \cdot \mathrm{ha}^{-1}$, proporciona satisfatórios rendimentos de sementes puras viáveis e de forragem, com máxima eficiência técnica estimada para o rendimento de sementes, com dose de $120 \mathrm{~kg} \cdot \mathrm{ha}^{-1}$.

A remoção de 55\% dos meristemas apicais dos perfilhos primários pelo corte realizado 29 dias após a germinação, promove a formação de população de perfilhos férteis capazes de expressar alto potencial de rendimento de sementes.

O número de sementes por panícula e o peso de mil sementes são os componentes que apresentam maior correlação com o rendimento de sementes.

A irrigação suplementar não apresenta vantagens sobre o rendimento de sementes e de forragem, porém apresenta interação com as doses de nitrogênio, contribuindo para seu maior aproveitamento pela planta.

\section{REFERÊNCIAS}

BRASIL. Ministério da Agricultura e Reforma Agrária. Regras para Análise de Sementes. Brasília:SNDA/DNDV/CLAV, 1992. 365p.

CARÁMBULA, M.; ELIZONDO, J. Producción de semillas in gramíneas forrajeras. I. Importancia de la edad de las macollas e influencia del nitrógeno y de la defoliación. Boletim Estacion Experimental Paysandú, Paysandú, n.5, p.111-137, 1968.

CARÁMBULA, M. Producción de semillas de plantas forrajeras. Montevideo: Agropecuaria, 1981. 518p.

CRAUFURD, P.Q.; BIDINGER, F.R. Effect of the duration of the vegetative phase on shoot growth, development and yield in pearl millet (Pennisetum americanum (L.) Leeke). Journal of Experimental Botany, Oxford, v.39, p.124-139, 1988.
CRUZ, C.D. Programa GENES: versão Windows; aplicativo computacional em genética e estatística. Viçosa: UFV, 2001. 648p.

GARCIA-HUIDOBRO, J.; MONTEITH, J.L.; SQUIRE, G.R. Time, temperature and germination of pearl millet (Pennisetum typhoydes S. \& H.). Journal of Experimental Botany, Loughborough, v.33, n.133. p.297-302, 1982.

GERALDO, J.; ROSSIELLO, R.O.P.; ARAÚJO, A.P.; PIMENTEL, C. Diferenças em crescimento e produção de grãos de quatro cultivares de milheto pérola. Pesquisa Agropecuária Brasileira, Brasília, v.35, n.7, p.1367-1376, 2000.

LUPATINI, G.C.; MOOJEN, E.L.; RESTLE, J.; SILVA, J.H.S. Resposta do Milheto (Pennisetum americanum (L.)Leeke) sob pastejo à adubação nitrogenada. Pesquisa Agropecuária Brasileira, Brasília, v.31, n.10, p.715-720, 1996.

MARASCHIN, G. E. Potencial produtivo de gramíneas forrageiras de verão no sul do Brasil. Lavoura Arrozeira, Porto Alegre, n.315, p. 18-24, ago., 1979.

MEDEIROS, R.B.; SAIBRO, J.C.; JACQUES, A.V.A. Efeito do nitrogênio e da população de plantas no rendimento e qualidade de milheto (Pennisetum americanum Schum.). Revista da Sociedade Brasileira de Zootecnia, Viçosa, v.7, n.2, p.276-285, 1978.

MESQUITA, E.E. Efeito de doses de nitrogênio e métodos de semeadura no rendimento de sementes e de forragem de milheto (Pennisetum americanum (L.) Leeke), 1996. 86f. Dissertação (Mestrado em Zootecnia) Universidade Federal de Lavras, Lavras, 1996.

MESQUITA, E.E.; PINTO, J.C. Nitrogênio e métodos de semeadura no rendimento da forragem de pós-colheita de sementes de milheto (Pennisetum glaucum (L.) R. Br.). Revista Brasileira de Zootecnia, Viçosa, v.29, n.4, p.971-977, 2000.

MESQUITA, E.E.; PINTO, J.C.; MORAIS, A.R. Doses de nitrogênio e métodos de semeadura no rendimento de sementes de milheto (Pennisetum americanum (L.) Leeke). Revista Brasileira de Zootecnia, Viçosa, v.27, n.2, p.255-261, 1998.

MORAES, A.; MARASCHIN, G.E.; NABINGER, C. Pastagens nos ecossistemas de clima subtropical: pesquisas para o desenvolvimento sustentável. In: SIMPÓSIO SOBRE PASTAGENS NOS ECOSSISTEMAS BRASILEIROS, 12., 1995, Brasília. Anais... Brasília: SBZ, 1995. p.147-200.

NABINGER, C.; MEDEIROS, R.B. Produção de sementes de Panicum maximum Jacq.. In: SIMPÓSIO SOBRE MANEJO DA PASTAGEM, 12,, 1995, Piracicaba. Anais... Piracicaba: FEALQ, 1995. 345p.

QUENDEBA, B.; EJETA, G.; NYQUIST, W.E.; HANNA, W.W.; KUMAN, A. Heterosis and combining ability among african pearl millet landraces. Crop Science, Madison, v.33, n.4, p.735-739, 1993.

ROJAS, C.A.L. Alterações físico-hídricas de um podzólico em função do manejo do solo. 1998. 76f. Dissertação (Mestrado em Fitotecnia) Faculdade de Agronomia, Universidade Federal do Rio Grande do Sul, Porto Alegre, 1998.

ROY, R.N.; WRIGHT, B.C. Effect of fertilizer aplication on morphology and weight components of the panicle of Sorchum bicolor (L.) Moench. Indian Journal of Agricultural Sciences, New Dehli, v.43, n.4, p.419-422, 1973. 
SCHEFFER, S.M. Efeito de doses de nitrogênio, métodos de estabelecimento e regimes de corte no rendimento e qualidade da semente e da forragem de milheto (Pennisetum americanum (L.) Leeke). 1981. 131 f. Dissertação (Mestrado em Zootecnia), Faculdade de Agronomia, Universidade Federal do Rio Grande do Sul, Porto Alegre, 1981.

SCHEFFER, S.M.; SAIBRO, J.C.; RIBOLDI, J. Efeito do nitrogênio, métodos de semeadura e regimes de corte no rendimento e qualidade da forragem e da semente de milheto. Pesquisa Agropecuária Brasileira, Brasília, v.20, n.3, p.309-317, 1985.

SILVEIRA, C.A.M.; SAIBRO, J.C.; MARKUS, R. Efeito do nitrogênio e regimes de corte sobre o rendimento e qualidade de milheto e sorgos forrageiros, sob condições de déficit hídrico.
Revista da Sociedade Brasileira de Zootecnia, Viçosa, v.13, n.2, p.141-152, 1984.

SUBBA REDDY, G.; VENKATESWARLU, B.; VITTAL, K.P.R.; SANKAR, G.R.M. Effect of different organic materials as source of nitrogen on growth and yield of sorghum (Sorghum bicolor). Indian Journal of Agricultural Sciences, New Dehli, v.61, n.8, p.551-555, 1991.

YOUNG III, W.C.; CHILCOTE, D.O.; YOUNGBERG, H.W. Annual ryegrass seed yield response to grazing during early stem elogation. Agronomy Journal, Madison, v.88, p.211-215, 1996.

ZONTA, E.P.; MACHADO, A.A. Sistema de análise estatística para microcomputadores SANEST. Pelotas: UFPel, 1984.

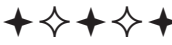

